\title{
Les persécutions contre le Christianisme sous Inoue Masashige (1640-1658) et la débâcle de Kōri (1657-1658)
}

\section{Martin Nogueira Ramos}

\section{(2) OpenEdition Journals}

Édition électronique

URL : https://journals.openedition.org/cipango/170

DOI : 10.4000/cipango. 170

ISSN : 2260-7706

Éditeur

INALCO

Édition imprimée

Date de publication : 1 janvier 2008

Pagination : 297-299

ISBN : 978-2-85831-177-4

ISSN : 1164-5857

Référence électronique

Martin Nogueira Ramos, « Les persécutions contre le Christianisme sous Inoue Masashige (1640-1658) et la débâcle de Kōri (1657-1658) », Cipango [En ligne], 15 | 2008, mis en ligne le 14 novembre 2011, consulté le 30 juin 2021. URL : http://journals.openedition.org/cipango/170 ; DOI: https://doi.org/10.4000/cipango.170

Ce document a été généré automatiquement le 30 juin 2021.

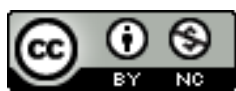

Cipango est mis à disposition selon les termes de la Licence Creative Commons Attribution - Pas d'Utilisation Commerciale 4.0 International. 


\title{
Les persécutions contre le Christianisme sous Inoue Masashige (1640-1658) et la débâcle de Kōri (1657-1658)
}

\author{
Martin Nogueira Ramos
}

\section{RÉFÉRENCE}

Les persécutions contre le Christianisme sous Inoue Masashige (1640-1658) et la débâcle de Kōri (1657-1658), Mémoire de Master 2 soutenu par Martin Nogueira Ramos (Paris 7-Diderot, 2008), sous la direction d'A. Horiuchi.

1 Le propos de ce mémoire est d'étudier la question des persécutions contre la religion chrétienne après l'expulsion des Portugais (1639) ainsi qu'après la disparition quasi totale du clergé catholique. J'ai choisi de focaliser mes recherches sur Inoue Chikugo no kami Masashige 井上筑後守政重, le premier Shūmon aratame yaku 宗門改役 (1640-1658), une fonction que certains historiens occidentaux ont traduit par le terme « inquisiteur ». J'ai axé mon étude de cette période sur deux sources : Le Kirisuto-ki 契利 斯督記 et le Ōmura kenmon-shū 大村見聞集. Le Kirisuto-ki nous est parvenu sous la forme d'une compilation effectuée en 1797 par un penseur confucéen du fief de Fukuyama, Ōta Zensai 太田全斎, de textes écrits entre 1652 et 1662 par des fonctionnaires du Shūmon aratame. Il est important de noter que ces textes n'étaient pas voués à être diffusés, ils avaient sans doute un usage interne. J'ai proposé une traduction française des chapitres 3, 7 et 11. Sur un certain nombre de points, ma version est différente de la traduction allemande effectuée dans les années 1930 par Hubert Cieslik S.J et Gustav Voss. Les chapitres 5 et 7 abordent les moyens utilisés par le Shūmon aratame pour trouver des chrétiens ainsi que le traitement qui leur était infligé. Le chapitre 11 expose une liste d'arguments permettant de réfuter le christianisme en 
insistant notamment sur ses contradictions doctrinales, évidentes selon les auteurs du texte.

La seconde source utilisée, les chapitres 39, 40 et 41 du Ōmura kenmon-shū, présentent un cas d'arrestation massif de chrétiens (plus de 600 individus) dans le fief d'ōmura entre la fin de l'année 1657 et août 1658 : le Kōri kuzure 郡崩机. Le Ōmura kenmon-shū a été rédigé dans les années 1830 par deux guerriers de ce fief. Les sujets abordés sont divers (les relations avec Nagasaki, le christianisme, les problèmes de succession dans la famille d'ōmura, la chasse à la baleine, la vie paysanne, etc...). Concernant le Kōri Kuzure, les chapitres 39, 40 et 41 sont composés de rapports effectués par les fonctionnaires du fief en charge de l'arrestation des chrétiens à l'époque des événements. À l'origine, je souhaitais par l'exemple du Kōri kuzure étudier un cas d'arrestation de chrétiens sous Inoue Masashige. Cependant, l'étude de la source a montré qu'il n'a pas participé aux opérations menées dans le fief contre le christianisme à l'époque des événements. Le Magistrat de Nagasaki, Kurokawa Masanao 黑川正直, s'est chargé de l'essentiel des opérations avec l'appui des guerriers du fief d'ōmura.

3 Ainsi, une grande partie de mon mémoire, à l'exception du dernier chapitre, est basée sur l'étude comparative des méthodes de lutte contre le christianisme dans le Kirisuto-ki et lors du Kōri Kuzure. Schématiquement, on peut dire qu'on observe un durcissement des sanctions, symbolisé par le recours quasi-systématique à la peine de mort (environ $80 \%)$ lors de l'arrestation de chrétiens dans le fief d'Ōmura. Ainsi, le nombre de chrétiens arrêtés à Kōri fut bien plus important que sous Inoue Masashige. Le Kōri Kuzure marque un tournant dans l'histoire de l'interdiction du christianisme au Japon. Entre 1657 et la fin des années 1670, les communautés chrétiennes appréhendées par le Bakufu sont sévèrement réprimées. Jusqu'alors les autorités se contentaient d'arrestations ponctuelles, de méthodes non-violentes comme l'usage de la prédication de moines bouddhistes, voire même d'un certain laisser-faire. J'ai présenté dans une autre partie le rôle du Shümon aratame yaku, véritable coordinateur de l'action du Bakufu contre le christianisme jusqu'à l'affaire de Kōri où il cède temporairement sa place au Magistrat de Nagasaki. La question de la pratique et de la foi des kakure kirishitan 隠れキリシタン a aussi été traitée. Alors que l'on étudie généralement cette question dans le cadre d'enquêtes de terrain, je me suis exclusivement basé sur les sources écrites mentionnées ci-dessus. Concernant les chrétiens d'ōmura, un mouvement eschatologique prévoyant la fin du monde pour décembre 1657 est à l'origine des arrestations menées par les autorités. On peut rapprocher ce mouvement de la révolte de Shimabara qui elle aussi eut des accents eschatologiques comme l'a montré Ōhashi Yukihiro dans son ouvrage Kenshō Shimabara Amakusa ikki 検証島原天草 一揆 (Yoshikawa kōbunkan, 2008). Dans une dernière partie, les arguments utilisés pour lutter contre le christianisme qui se trouvent dans le chapitre XI du Kirisuto-ki ont été analysés. Une grande partie de ces arguments se retrouve dans le Ha-Daiusu 破提宇 子 de Fabian Fucan 不干.

4 Ces questions ont été relativement peu abordées par l'historiographie japonaise et encore moins par les Occidentaux si ce n'est concernant l'histoire intellectuelle. L'arrestation des chrétiens de Kōri a été peu traitée. La seule étude complète de la question datant de 1930 est très événementielle. Concernant la question du traitement du christianisme à l'époque d'Edo, on peut citer trois historiens principaux. Ōhashi Yukihiro a intégré la période 1640-1658 dans une étude plus vaste du christianisme à 
l'époque d'Edo en analysant, notamment, ses interactions avec le pouvoir régional et central. 